\title{
INTECOL 2013 INTO THE NEXT 100 YEARS
}

\author{
XI International Congress of Ecology \\ (London, UK, $18^{\text {th }}-23^{\text {rd }}$ August 2013)
}

The Congress organized by INTECOL and the British Ecological Society was held in London on $18^{\text {th }}-23^{\text {rd }}$ August, 2013. 2065 delegates from 67 countries, across all continents, from students to eminent Professors participated in the Congress. Throughout the 6 days of the conference there were 11 plenary talks, 16 parallel sessions, 44 symposia, 1080 oral presentations, 580 poster presentations, and 30 workshops. The conference reflected the international ecological science taking place across the world today, and a very broad spectrum of different ecological problems were presented and discussed. However, the issues taken into consideration most frequently were biodiversity, the impacts of climate change on ecosystems and on flora and fauna, ecosystem services, the ecological consequences of evolutionary change, basic science in ecology, global change and ecosystem ecology, light pollution in an urbanized world, compensation mechanisms in plants, phenology and climate, invasive organisms, threats to ecosystem services, multifunctionality of the landscape, energy flows and matter cycling, and many others.

The Congress program included ten world-class plenary speakers, symposia featuring major keynote lectures, workshops, submitted abstract sessions and extended poster slots. Other features included innovative ways of presenting and communicating science, and a program structured to allow many opportunities for networking. This Congress gave delegates a new perspective on a wide range of ecological topics and helped establish new collaborative partnerships.

One Symposium, Tools to enhance landscape resilience to human impact, was organized by: 1) the Institute for the Agricultural and Forest Environment, Poznan, Poland, 2) the Polish Academy of Sciences, Polish National Committee on Global Change - GBP and 3) Adam Mickiewicz University, Dept. Integrated Geography, 
Poznań, Poland. The keynote paper on Shaping the landscape structure to mitigate the effects of climate change and anthropopressure in rural areas was delivered by Prof. Andrzej Kędziora of the Institute for the Agricultural and Forest Environment, PAS (Poland). The seven papers delivered overall concerned: The importance of landscape structure for diversification of climatic conditions on the regional scaleProf. A. Mizgajski (Poland); A Next "Dust Bowl" in Siberia!? - Adaptations with land use innovations to prevent that - Prof. M. Fruehauf (Germany); Water management in urban areas as a result of increasing urbanization - Prof. P. Kowalczak (Poland); How does "green infrastructure" mitigate the loss of ecosystem service in agricultural normal landscapes of Central Europe? - Prof. T. Buttschardt (Germany); Can bioenergy production contribute to resiliency in managed landscapes? - Prof. R. Lowrance (USA); and Correlating species abundance with its use value to assess anthropogenic pressures on vegetation of the western Himalayas - Dr. S. Khan (Pakistan).

Presentations brought together at the symposium consider a new approach to sustainable rural development. Means proposed for adaptation to and the mitigation of adverse climate change and land use are based on the latest knowledge on environmental management in selected regions of Central Asia (Siberia), Central Europe and the United States, regions located in the temperate zone. They show how we can provide for the maintenance of ecosystems services essential to the development of civilization, while maintaining high agricultural production and energy security. They have an interdisciplinary character resulting from a holistic approach to the environmental, social, and economic processes. The set of presentations is a cohesive whole, passing from more general issues (Papers 1-3) showing the principles in line with which the structure of regions and landscapes takes shape, and their interaction with such processes as energy flow and the circulation of matter, especially as regards the impact on phenomena occurring in lower layers of the atmosphere; through issues related to specific ecosystems (Papers 4-7) to the issue of how spatial planning may be utilized in landscape management. The attention is always focused on the possibilities for adaptation to, and the mitigation of, adverse effects of climate change and land use, with use being made of natural processes and mechanisms, as supported by technical measures.

Andrzej Kędziora

Institute for the Agricultural and Forest Environment Polish Academy of Sciences 